\title{
TESTING OF GNSS MULTIPATH IN DIFFERENT OBSERVATIONAL CONDITIONS AT ONE STATIONARY STATION
}

\author{
Jakub KOSTELECKÝ ${ }^{1)}$, Jan KOSTELECKÝ ${ }^{1,2)} *$ and Pavel VÁCLAVOVIC ${ }^{1)}$
}

${ }^{1)}$ Research Institute of Geodesy, Topography and Cartography, GO Pecný - NTIS, 25165 Ondrejov 244, Czech Republic
${ }^{2)}$ Faculty of Mining and Geology, VŠB TU Ostrava, 17 listopadu 15, 70833 Ostrava, Czech Republic

*Corresponding author's e-mail: kost@fsv.cvut.cz

\begin{tabular}{l} 
ARTICLE INFO \\
\hline Article history: \\
Received 2 May 2017 \\
Accepted 31 August 2017 \\
Available online 25 September 2017 \\
\hline Keywords: \\
GNSS \\
Multipath \\
Observing conditions
\end{tabular}

\section{INTRODUCTION}

The aim of the work was to analyze temporal changes of the impact of multipath propagation of GNSS pseudo-range signal used for positioning (determined via code pseudorange observations) during the calendar year, depending on weather conditions change (especially as a result of foliage of trees, changes in surfaces reflectance due to rain or snow, etc.). The analysis was performed on the sequences of one day data measured on a stationary point.

\section{EXPERIMENT TEST OF MULTIPATH}

\subsection{DESCRIPTION OF THE EXPERIMENT}

The experiment - long-term GNSS measurements to monitor changes in multipath propagation errors GNSS signal - was implemented at the field laboratory of the Research Institute of Geodesy, Topography and Cartography, v.v.i. Geodetic Observatory Pecný in Ondřejov near Prague.

For measurements it was selected position, from which the view of the sky is limited by nearby buildings, structures, and particularly metal shed deciduous and coniferous woods. The following photos show the location of before-described obstacles in the area. The simple plan describes the distances to the biggest obstacle - the main building of the observatory.

Covering of the "sky plot" shows the Figure 2.

\subsection{DATA}

The Trimble SPS855 receiver with antenna Trimble Zephyr Model 2 was used for measurements in experiment to receive signals on two frequencies of GNSS navigation systems NAVSTAR GPS and GLONASS, however, only data from the NAVSTAR GPS were processed. The registration of meteorological data was concurrently performed (especially temperature, humidity and atmospheric pressure).

Basic measurement unit is one day (24 hours), which was determined with respect to maximizing the sky coverage data from the satellites from different directions. Because the NAVSTAR GPS satellites configuration is repeated with a period of 24 hours sidereal time, it makes no sense to extend the basic measurement unit for several days.

From the measured period (from winter to summer 2015) were selected measurement days, during which the situation in the surrounding obstacles is stable (e. g. permanent snow, rain etc.), and during which it was carried out photographic documentation of the state of the surface and the foliage of trees. Finally, it was selected 23 days for further analysis. The selected data including a description of the situation of surrounding obstacles summarized in the following Table 1 (DOY is the number of day in 2015).

\subsection{PROCESSING OF THE MEASUREMENT}

Measured data from GNSS technology - daily files - were tested in terms of multipath signals 
Table 1 Observation Conditions

\begin{tabular}{lrcll}
\hline DOY & Date & snow & leaves & message \\
\hline 037 & 6.2 .2015 & yes & no & $\begin{array}{l}\text { part of } \\
\text { day }\end{array}$ \\
& & & & \\
041 & 10.2 .2015 & yes, melting & no & \\
043 & 12.2 .2015 & yes, partly & no & \\
044 & 13.2 .2015 & very small & no & \\
050 & 19.2 .2015 & very small & no & \\
062 & 3.3 .2015 & no & no & wet \\
065 & 6.3 .2015 & no & no & dry \\
069 & 10.3 .2015 & no & no & dry \\
077 & 18.3 .2015 & no & no & dry \\
083 & 24.3 .2015 & no & no & \\
086 & 27.3 .2015 & no & no & wet \\
089 & 30.3 .2015 & no & no & \\
092 & 2.4 .2015 & yes & no & \\
093 & 3.4 .2015 & yes & no & \\
105 & 15.4 .2015 & no & weak sprout- & \\
& & & ing leaves & \\
107 & 17.4 .2015 & no & small leaves & wet \\
110 & 20.4 .2015 & no & young leaves & \\
114 & 24.4 .2015 & no & yes & wet \\
124 & 4.5 .2015 & no & yes & wes \\
125 & 5.5 .2015 & no & yes & wet \\
126 & 6.5 .2015 & no & yes & wet \\
127 & 7.5 .2015 & no & yes & wet \\
133 & 13.5 .2015 & no & yes & wet \\
& & & &
\end{tabular}

(multipath) processed by software gNut-Anubis, which is being developed at Geodetic Observatory Pecný. Function of software is described in detail in (Václavovic and Douša, 2016).

Program gNut-Anubis (see e.g.

http://www.pecny.cz/gop/index.php/gnss/sw/anubis/a nubis-summary) calculated on the base of the GNSS RINEX set of measured data for a selected point in time: azimuth, elevation and multipath value for all satellites that were observed at this time. In our case, we focused on further processing only on GPS NAVSTAR satellites. In addition to the observation data file software still needs to calculate the appropriate navigation file.

Value multipath $M C$ for frequencies $i, j, k$ is

$M C_{k}=P_{k}-L_{i}-\frac{2 f_{j}^{2}}{f_{i}^{2}-f_{j}^{2}}\left(L_{i}-L_{j}\right)$

Value multipath on $C_{1}$ code is calculated according to the expression

$M C_{1}=P_{1}-L_{1}-\frac{2 f_{2}^{2}}{f_{1}^{2}-f_{2}^{2}}\left(L_{1}-L_{2}\right)$

and on the $C_{2}$ code

$M C_{2}=P_{2}-L_{2}-\frac{2 f_{1}^{2}}{f_{2}^{2}-f_{1}^{2}}\left(L_{2}-L_{1}\right)$,

where $P_{i}$ is the pseudorange, $L_{i}$ is a "phase of carrier frequency", expressed in meters, and $f_{i}$ is the corresponding frequency. Phase jumps ("cycle slips") for $L_{i}$ are computed using linear combinations of $L_{4}$
(Melbourn-Wubbena) or $L_{6}$ - see (Václavovic and Douša, 2016).

Multipath calculation is as follows:

For a given number of epochs that are configured through parameters in gNut-Anubis software (in our case it was 20) is determined for a particular signal (e.g., $M C_{1}$ ) via linear combination (1), which mainly contains multipath. The number of epochs must be continuous without phase jumps and follows a desired epoch, which is related to the resulting value. The resultant value of multipath is given by the dispersion of the results of the linear combination (1).

In the following text we encounter the term "quadratic mean value" (abbreviated RMS or graphic "root mean square"), which is defined as follows: the quadratic mean $m$ of $n$ values of $v$ is defined by the expression:

$m=\sqrt{\frac{\sum_{1}^{n} v_{i}^{2}}{n}}$.

Data processing into the final result was then carried out by the software:

- Multi-anubis-GPS.for which processes the results of the program-gNut Anubis and for a selected azimuth and elevation (step one degree) searches the maximum value (if the same azimuth, and elevation observed more satellites) multipath on each of the codes $\mathrm{C} 1$ and $\mathrm{C} 2$.

- Multi-Anubis-GPS-10.for that functions like a multi-program Anubis-GPS.for only seeks maximum and RMS multipath in a spherical trapezoid $10 \times 10$ degrees due clearer graphical interpretation of the results.

- "Working software" for combination of results of above mentioned software, results of it is "RMS" and maximum values "max".

Given the observational campaign was organized so that the south side of the forest and on the north side of the horizon was overshadowed by the building of the observatory was to select the observations decisive moments foliage of trees, snow cover and relative humidity. The results were shown in addition spreadsheet processing and graphically examples of multipath values for $\mathrm{C} 1$ and $\mathrm{C} 2$ are for DOY 037 in Figure 3. The complete set of images is subject of the research report (Kostelecký Jr. and Kostelecký, 2015).

\subsection{SUMMARY RESULTS}

The following Table 2 shows the numerical values of multipath in its entirety observed azimuth and altitude satellites. This is the maximum and the mean-square value (see above) for each day.

The following Table 3 shows the mean square value between two multipath somewhat extreme "conditions" of weather. Mean-square value is calculated on the grounds of destination "mean-square value of the effects of uncertainty" in determining the position of the code measurements. To calculate the differences were therefore selected days with different weather conditions. 
Table 2 Average of multipath in the whole range of azimuths and elevations, mean square values (RMS) and the maximum of multipath for each day.

\begin{tabular}{|c|c|c|c|c|c|c|c|c|c|c|}
\hline \multirow[b]{2}{*}{ DOY } & \multirow[b]{2}{*}{ date } & \multirow[b]{2}{*}{ snow } & \multirow[b]{2}{*}{ leaves } & \multirow[b]{2}{*}{ message } & \multicolumn{3}{|c|}{$\mathrm{C} 1$} & \multicolumn{3}{|c|}{$\mathrm{C} 2$} \\
\hline & & & & & $\begin{array}{c}\text { mean } \\
{[\mathrm{cm}]}\end{array}$ & $\begin{array}{l}\text { RMS } \\
{[\mathrm{cm}]}\end{array}$ & $\begin{array}{l}\max \\
{[\mathrm{cm}]}\end{array}$ & $\begin{array}{c}\text { mean } \\
{[\mathrm{cm}]}\end{array}$ & $\begin{array}{l}\text { RMS } \\
{[\mathrm{cm}]}\end{array}$ & $\begin{array}{l}\max \\
{[\mathrm{cm}]}\end{array}$ \\
\hline 37 & 6.2 .2015 & yes & no & part of day & 52 & 61.5 & 501 & 35.1 & 39.8 & 465 \\
\hline 41 & 10.2 .2015 & melting & no & & 53.3 & 61.7 & 299 & 36.4 & 41.1 & 349 \\
\hline 43 & 12.2 .2015 & partly & no & & 52.3 & 62.2 & 447 & 36 & 41.8 & 504 \\
\hline 44 & 13.2 .2015 & small & no & & 52.1 & 61.3 & 503 & 35.7 & 40.6 & 331 \\
\hline 50 & 19.2 .2015 & small & no & & 51.9 & 60.4 & 373 & 35.9 & 40 & 303 \\
\hline 62 & 3.3 .2015 & no & no & wet & 55 & 62.5 & 323 & 38.1 & 42.9 & 461 \\
\hline 65 & 6.3 .2015 & no & no & dry & 53.6 & 63.9 & 553 & 36.9 & 41.3 & 305 \\
\hline 69 & 10.3 .2015 & no & no & dry & 53.6 & 62.5 & 515 & 37.1 & 42.2 & 317 \\
\hline 77 & 18.3 .2015 & no & no & dry & 54.3 & 62.8 & 308 & 37.5 & 41.8 & 403 \\
\hline 83 & 24.3 .2015 & no & no & & 53.3 & 61.1 & 359 & 37.1 & 41.8 & 389 \\
\hline 86 & 27.3 .2015 & no & no & rain & 54.8 & 63.6 & 365 & 37.7 & 41.8 & 242 \\
\hline 89 & 30.3 .2015 & no & no & & 56.9 & 65 & 395 & 37.9 & 41.4 & 301 \\
\hline 92 & 2.4 .2015 & yes & no & & 55.5 & 63 & 412 & 37.6 & 41.6 & 278 \\
\hline 93 & 3.4 .2015 & yes & no & & 54.5 & 62.8 & 329 & 36.7 & 40.2 & 233 \\
\hline 105 & 15.4 .2015 & no & $\begin{array}{c}\text { weak sprouting } \\
\text { leaves }\end{array}$ & & 55.2 & 62.9 & 362 & 37.5 & 42.3 & 240 \\
\hline 107 & 17.4 .2015 & no & small leaves & wet & 53.4 & 61.4 & 280 & 35.6 & 39.2 & 292 \\
\hline 110 & 20.4 .2015 & no & young leaves & & 54.6 & 62.8 & 363 & 37.8 & 43 & 435 \\
\hline 114 & 24.4 .2015 & no & yes & & 51.8 & 59.5 & 346 & 35.5 & 38.4 & 181 \\
\hline 124 & 4.5 .2015 & no & yes & wet & 50.9 & 59.2 & 443 & 35.3 & 38.1 & 235 \\
\hline 125 & 5.5 .2015 & no & yes & wet & 50.6 & 57.8 & 410 & 35.4 & 39.5 & 363 \\
\hline 126 & 6.5 .2015 & no & yes & rain & 51.9 & 59.2 & 511 & 35.2 & 37.2 & 262 \\
\hline 127 & 7.5 .2015 & no & yes & wet & 52 & 58.4 & 268 & 35.3 & 38.3 & 227 \\
\hline 133 & 13.5 .2015 & no & yes & wet & 49.7 & 56.5 & 467 & 36.1 & 39.8 & 263 \\
\hline
\end{tabular}

Table 3 Mean square value of difference (dRMS) in its entirety azimuths and elevations and the maximum mean values of the difference between two multipath periods (DOY1 minus DOY2).

\begin{tabular}{lllcrr}
\hline & & \multicolumn{2}{c}{$\mathrm{C} 1$} & \multicolumn{2}{c}{$\mathrm{C} 2$} \\
\cline { 3 - 6 } DOY1 - DOY2 & difference of states & dRMS [cm] & max [cm] & dRMS [cm] & max [cm] \\
\hline $037-038$ & no & 11.4 & 100 & 10.5 & 95 \\
$037-065$ & snow/without snow & 22.6 & 191 & 16.4 & 127 \\
$069-071$ & no & 14.5 & 116 & 8.7 & 74 \\
$069-086$ & dry/wet & 17.6 & 111 & 12.6 & 97 \\
$083-133$ & trees & 13.4 & 104 & 15.3 & 112 \\
& plane /leafed & & & & 15.3 \\
$104-105$ & no & 11.0 & 64 & 156 & 156 \\
$124-125$ & no & 11.0 & 47 & 12.3 & 131 \\
\hline
\end{tabular}

\section{CONCLUSION}

The analyzed differences of the multipath propagation (multipath) between two, somewhat extreme climatic conditions show, that can be stated: the significant differences in multipath propagation are only in a specific direction to the satellites. The average values vary considerably less. Dependence on changing conditions (seasons) does not significantly change the value of multipath.

Given the relatively very unfavorable configuration of the experiment, the mean square value of the multipath $C 1$ is to about $60 \mathrm{~cm}$ and to $40 \mathrm{~cm}$ for $C 2$. The dependence on the weather conditions varies between 10 and $20 \mathrm{~cm}$.

\section{ACKNOWLEDGMENT}

The experiment was carried out in the framework of contract research tied to the project
Technology Agency TB0200MD051, workplace NTIS in VÚGTK, v.v.i. Processing of obtained observing data were computed in the frame of LO1506 (PUNTIS) and project LM2015079 CzechGeo / EPOS.

\section{REFERENCES}

Kostelecký, J. Jr. and Kostelecký, J.: 2015, Processing long stationary measuring the impact of multipath propagation of GNSS signal at the Geodetic Observatory Pecný. Comprehensive Research Report 1241/2015. VÚGTK, v.v.i., Zdiby, 127 pp, (in Czech).

Václavovic, P. and Douša, J.: 2016, G-Nut/Anubis: Opensource tool for multi-GNSS data monitoring with a multipath detection for new signals, frequencies and constellations. In: IAG Symposia Series, Rizos, Ch. and Willis, P. (eds), Springer, 143, 775-782. DOI: 10.1007/1345_2015_97 

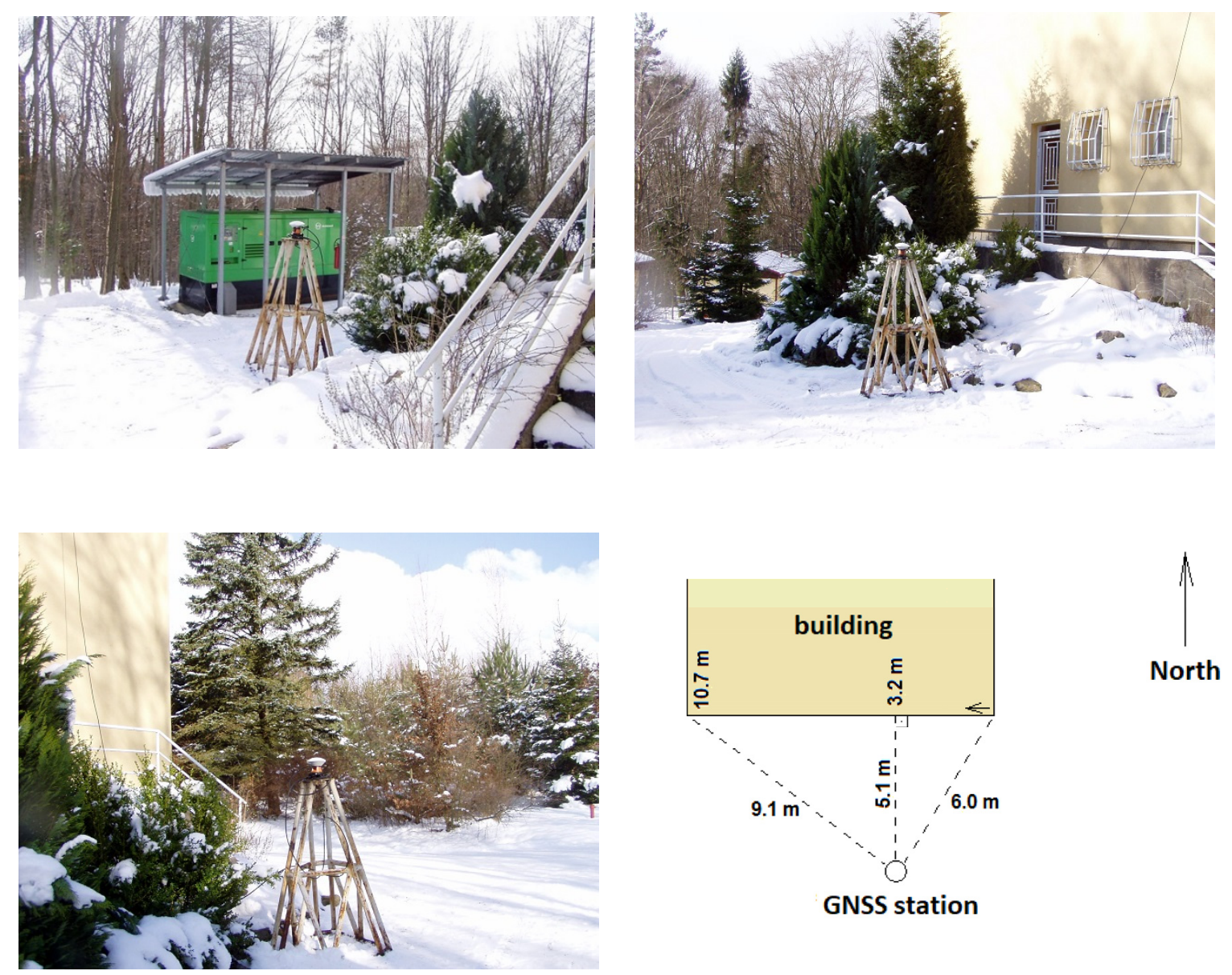

Fig. 1 Antenna location in the experiment - pictures left to right and down: a view towards SW, looking towards the north, looking towards the SE and the "situation".

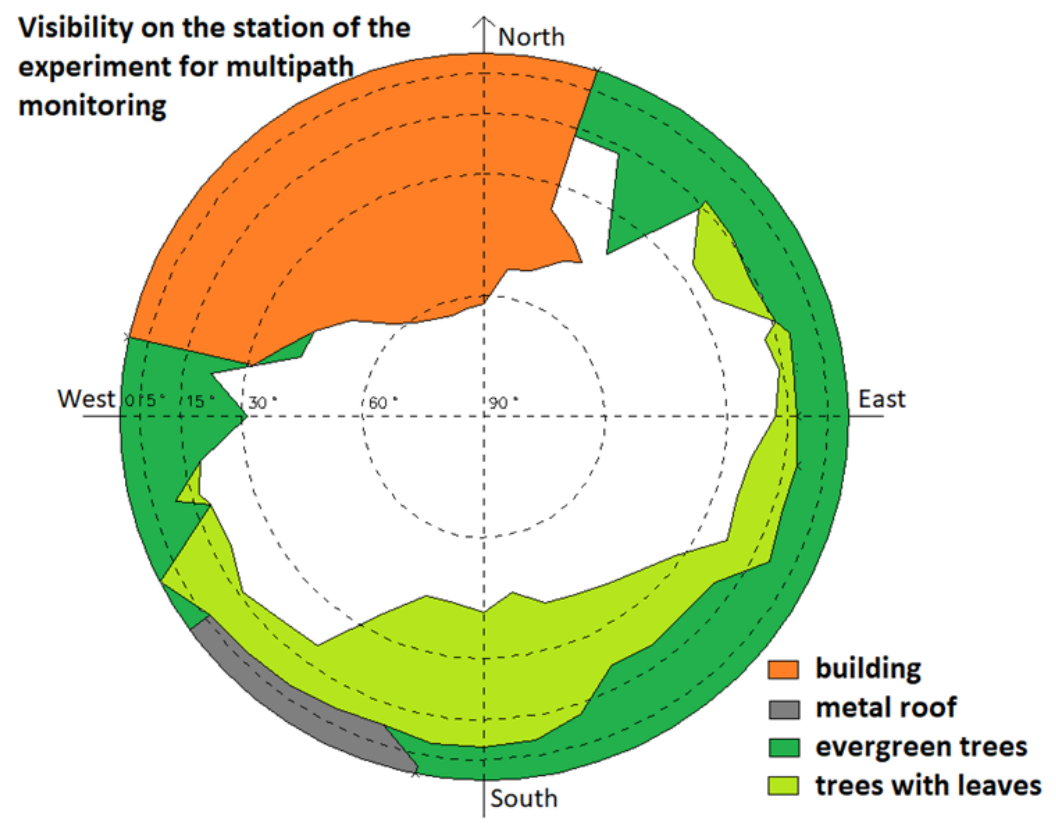

Fig. 2 Visibility charts of the sky plots on the station. 

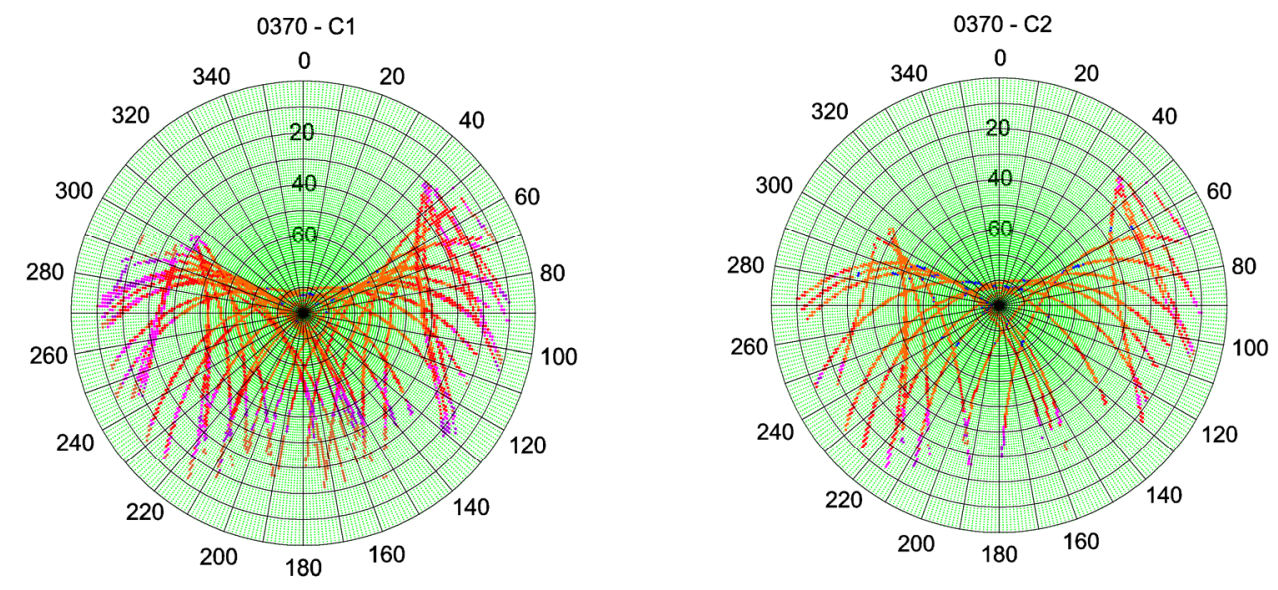

$$
\begin{array}{|l|}
\text { cm } \\
0 \text { to } 1 \\
1 \text { to } 20 \\
20 \text { to } 40 \\
40 \text { to } 60 \\
60 \text { to } 80 \\
80 \text { to } 100 \\
100 \text { to } 500 \\
\hline
\end{array}
$$

\begin{tabular}{|l|}
\hline $\mathrm{cm}$ \\
0 to 1 \\
1 to 20 \\
20 to 40 \\
40 to 60 \\
60 to 80 \\
80 to 100 \\
100 to 500 \\
\hline
\end{tabular}
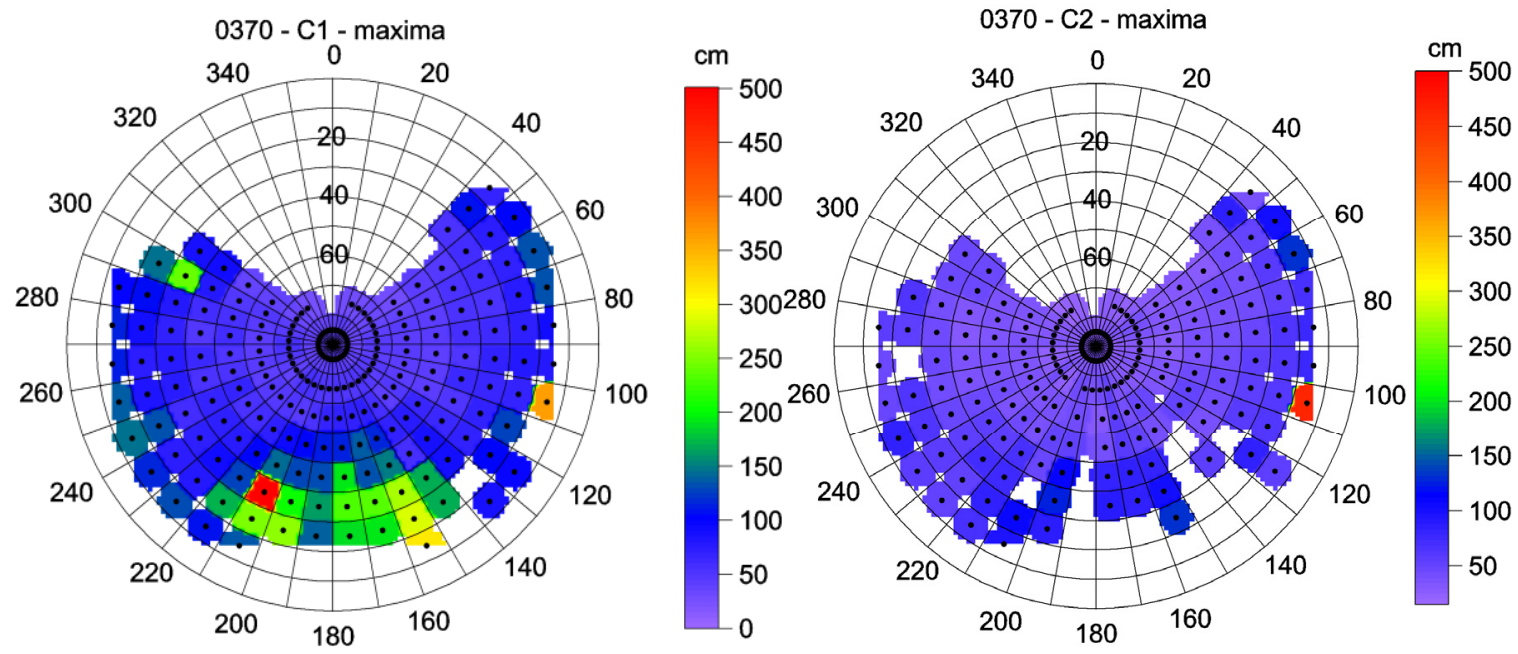

Fig. 3 Examples of detected multipath. 